\title{
Evaluation of Clinical Outcomes in Neonates Undergoing Lung Resection for Congenital Lesions
}

\author{
Hemonta Kumar Dutta ${ }^{1}$ Madhuchanda Bora ${ }^{2}$ Diganta Saikia ${ }^{2}$ \\ ${ }^{1}$ Department of Pediatric Surgery, Assam Medical College, Dibrugarh, \\ Assam, India \\ 2 Department of Anaesthesiology, Assam Medical College, Dibrugarh, \\ Assam, India \\ Address for correspondence Hemonta Kumar Dutta, MBBS, MS, MCh \\ Assam Medical College, APQ-8, L-lane, Dibrugarh, P.O. Borbari, Pin \\ 786002, Assam, India (e-mail: hemontdut@gmail.com). \\ J Child Sci 2017;7:e4-e9.
}

\begin{abstract}
Objective The purpose of this study is to review our experience with neonates and infants with congenital lung lesions emphasizing natural history, management, and outcomes.

Methods A total of 29 neonates and infants presented with congenital lung lesions between 2000 and 2015. Two patients died before surgery due to complications, and one patient refused surgery. Overall, 26 of them were subjected to surgical treatment and were included in the study. Demographic data, indications for surgery, operative procedure, complications, hospital stay, and follow-up were assessed.

Results A total of 26 children aged 5 to 122 days (mean: 35.5 days, 14 males) presented with various congenital lung malformations: congenital lobar emphysema in 10 , congenital cystic adenomatous malformation in 8 , bronchogenic cyst in 5 , and pulmonary sequestration in 3 patients. Respiratory distress and respiratory tract infection were the most common presenting symptoms noted in 22 patients. In three patients the lesion was

\section{Keywords}

- congenital lung cyst

- lung malformations

- congenital lobar emphysema

- congenital cystic adenomatous malformation

- bronchogenic cyst

- lung sequestration detected incidentally on chest X-ray. Lobectomy was the most common operation (19/26). Postoperative complications were noted in 12 patients. One patient died due to postoperative sepsis. Postoperative ventilation was required in 24 patients. Patients in the asymptomatic group recovered without any complications. The follow-up period ranged from 3 months to 15 years (median: 76.3 months). Only 12 patients received epidural anesthesia and had a better recovery than the other patients.

Conclusion Congenital lobar emphysema was the most common congenital lung lesion in our series. Respiratory distress and respiratory infection were the most common symptoms. Neonates and infants tolerated lung resection well. Use of epidural anesthesia led to less postoperative complications.
\end{abstract}

\section{Introduction}

Congenital lung malformations represent 5 to $18.7 \%$ of all congenital anomalies. Management of asymptomatic congenital pulmonary malformations remains controversial when addressing the optimal timing of surgical resection. Neonatal resection is advocated by some based on the theory that earlier lobectomy results in greater compensatory lung growth. This report is to review our experience with neo-

received

April 9, 2017

accepted

April 29, 2017 nates and infants with congenital lung lesions emphasizing natural history, management, and outcomes.

\section{Materials and Methods}

A total of 29 neonates and infants presented with congenital lung lesions between 2000 and 2015. Two patients died before surgery due to complications and one patient refused surgery. Overall, 26 of them were subjected to surgical

Copyright @ 2017 Georg Thieme

Verlag KG Stuttgart · New York

License terms

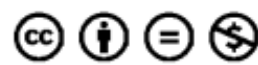


treatment and with the institutional review board approval, were included in the study. Demographic data, indications for surgery, operative procedure, complications, hospital stay, and follow-up, were assessed.

\section{Results}

A total of 26 patients aged 5 to 122 days (mean: 35.5 days, 14 males) were evaluated. Overall, 10 patients had congenital lobar emphysema (CLE), 8 had congenital cystic adenomatous malformation (CCAM), 5 had a bronchogenic cyst, and 3 patients had pulmonary sequestration. Respiratory distress and respiratory tract infection (RTI) were the most common presenting symptoms noted in 22 patients (84.6\%), and in 3 patients the lesion was an incidental finding on chest X-ray. One patient with CCAM presented with an intercostal chest tube inserted elsewhere for empyema. Lobectomy was the most common operation (19/26). Five patients had intraoperative problem, difficult intubation, bleeding, hypotension, and desaturation. Significant postoperative complications occurred in 12 patients: prolonged air leak or chest tube drainage (3), bronchopleural fistula (2), bleeding (2), respiratory distress requiring reintubation (1), contralateral pneumothorax (1), and sepsis (3). One patient died due to postoperative sepsis. A total of 24 patients were electively ventilated following surgery and 6 patients required ventilator support for more than 5 days, the longest being 15 days. The patients in the asymptomatic group recovered without any complications. Elective extubating was easier in older infants as compared with younger patients. The follow-up period ranged from 3 months to 15 years (median: 76.3 months). Only 12 patients received epidural anesthesia and had a better recovery than the other patients.

\section{Discussion}

Although rare, congenital lung malformations can cause considerable morbidity and mortality. Small lesions may remain asymptomatic for a considerable time. Failure to recognize a malformation may lead to inappropriate intervention and unnecessary complications. Successful treatment of such lesions became possible with regular use of endotracheal intubation and mechanical ventilation in the early 1950s. Gross and Lewis first successfully performed lobectomy in 1943 in a child with CLE. ${ }^{1}$ With the advent of laparoscopic surgery, many of the congenital lung malformations are now operated by thoracoscopic methods. ${ }^{2}$

CLE is a rare malformation of the lung with a prevalence of 1 in 20,000 to 1 in 30,000 births and characterized by hyperinflation of one or more pulmonary lobes. ${ }^{3-5}$ Males are affected more than females in a ratio of $3: 1 .^{3}$ In approximately $25 \%$ of the cases a definite obstructive cause can be found; intrinsic causes, such as bronchial cartilage deficiency are more common than the extrinsic causes. Due to lobar over distention and air trapping compressive changes were found in the rest of the lung (-Fig. 1). In about a third of patients, the number of alveoli increases (polyalveolar lobe). ${ }^{6}$ Respiratory distress and RTI were the commonest presenta-

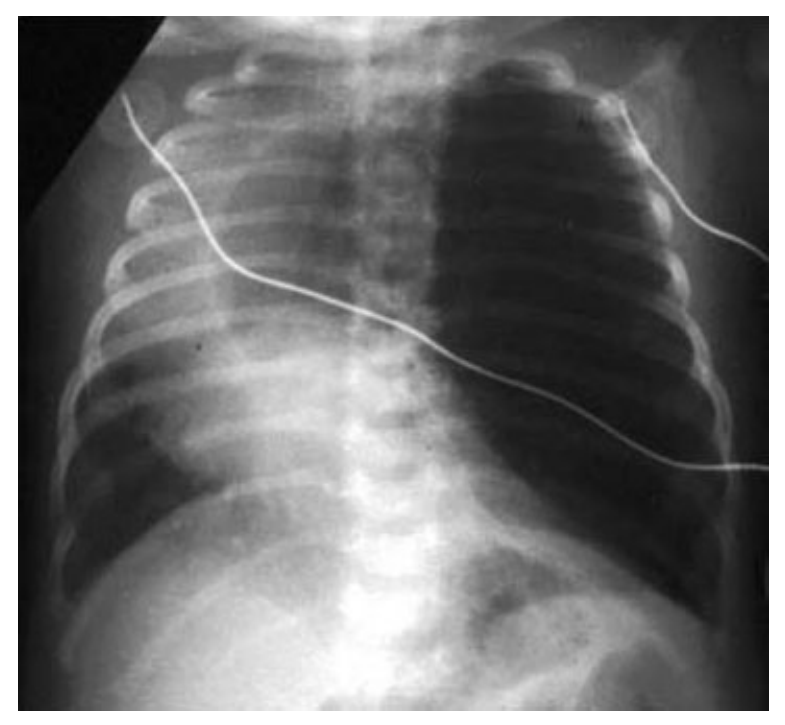

Fig. 1 Chest X-Ray of a child with CLE. CLE, congenital lobar emphysema.

tions in our series. Lobectomy was needed in all the 10 patients; left upper lobe was involved in 6 , right middle lobe in 3 , and right upper lobe in 1 patient. Four patients needed emergency lobectomy because of severe respiratory distress. Six patients were electively ventilated, and three patients needed postoperative ventilator support for poor respiratory efforts. One patient developed contralateral pneumothorax on postoperative day 3 requiring intercostal intubation; another two patients had prolonged air leak from the intercostal tube, which closed spontaneously. One patient needed ventilator support for 13 days for pneumonia.

CCAM results when the terminal bronchiolar component of the advancing endodermal lung bud proliferates haphazardly. Primary deficiency is the segmental bronchial atresia with the growth of secondary dysplastic lung beyond the atretic segment. ${ }^{7}$ CCAM usually appears before 7 weeks' gestation but can occur in the mid stage of lung development and the growth plateau at 28 weeks' gestation. ${ }^{4}$ Communication with the normal airways can lead to overinflation and compression of the surrounding lung tissue. Due to the large sonographic volume of CCAM in relation to head circumference, the chances of developing hydrops because of more severe central venous compression are greater. Stocker classified CCAM into three types according to the size of the cyst. ${ }^{8}$ Six of our cases were the macrocystic type, and two were type II with cyst less than $1 \mathrm{~cm}$ (-Fig. 2A, B). None of our patients had hydrops. Lobectomy was performed in all the patients (-Fig. $\mathbf{2 C}$ ). Two of them developed bronchopleural fistula, requiring rethoracotomy and repair in one, and the fistula closed spontaneously in the other patient. Three patients had prolonged intercostal tube drainage, two of them recovered, but one patient died because of septicemia. All the other patients are doing well at follow-up (-Fig. 2D).

Bronchogenic cysts represent outpouchings of the ventral foregut in the early part of gestation. These outpouchings arise close to the bronchial tree. A cyst may become infected, or it 


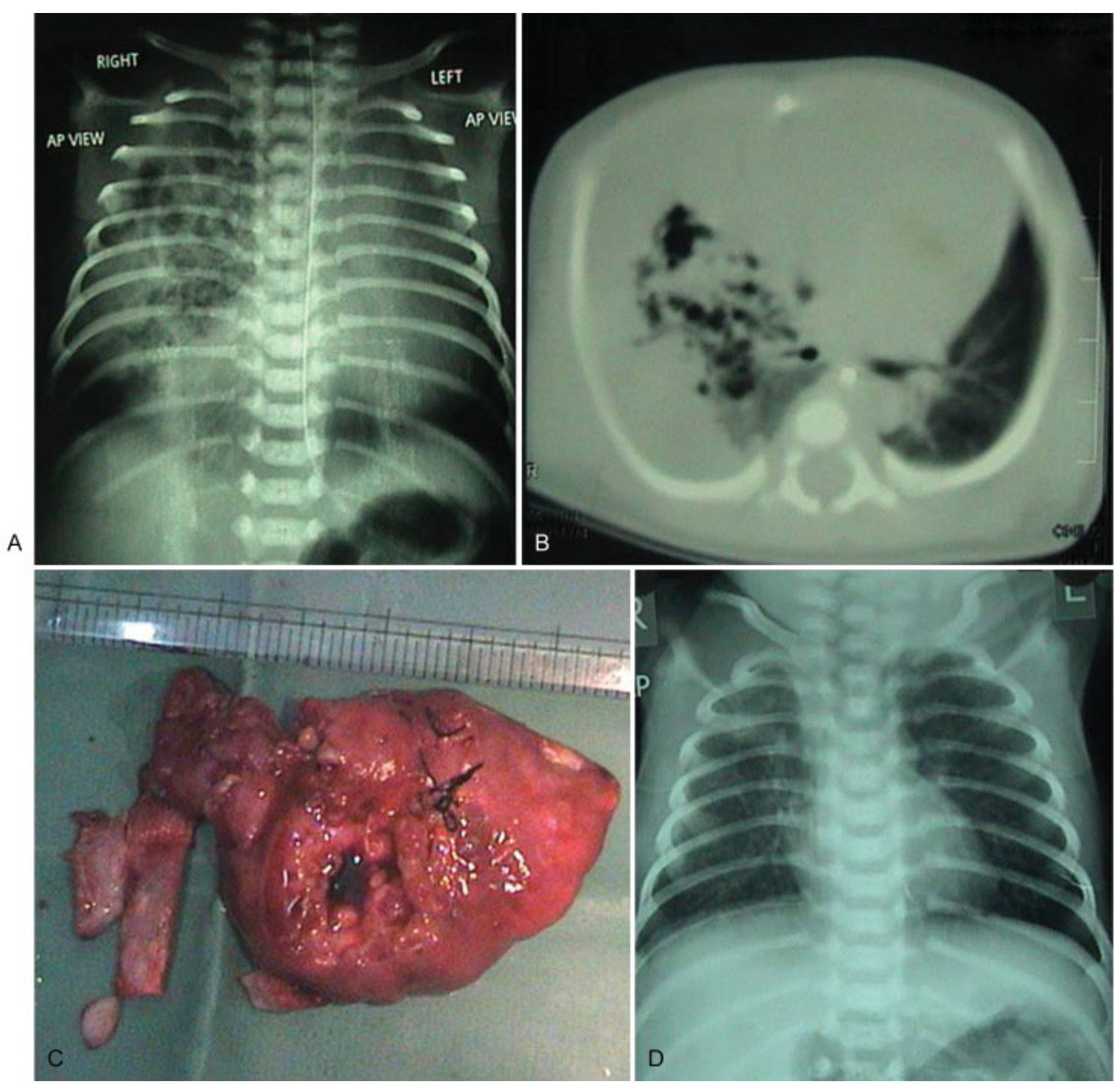

Fig. 2 (A) Preoperative chest X-ray of a child with CCAM. (B) CT scan thorax of the same child. (C) Excised specimen of CCAM. (D) Postoperative chest $\mathrm{X}$-ray of the same child. CCAM, congenital cystic adenomatous malformation; $\mathrm{CT}$, computed tomography.

may compress adjacent structures to produce signs and symptoms (-Fig. 3A). The cyst can be intrapulmonary (70\%) or mediastinal (30\%). Peripheral cysts appear late in gestation and are multiple. Complications can arise leading to pneumothorax, bronchopleural fistula, ulceration of the chest wall, and hemorrhage. Large cysts require excision, but small cyst can be observed and followed up. Of the five cases in our series, three were females, and four patients were symptomatic. Excision of the cyst alone was possible in three cases, in two patients lobectomy was necessary (-Figs. 3B, C). All the patients recovered well.

Sequestration is a mass of nonfunctioning lung tissue without normal bronchial or vascular connections. The sequestration could be intra (IL) or extralobar (EL), and two-thirds occur in the left lung. Both types obtain their blood supply from the aorta or its branches. Sequestrations may also be connected to the gastrointestinal tract. Neonates or infants with IL sequestration present with feeding diffi- culties, failure to thrive, dyspnea, cyanosis, or respiratory distress. In almost a third of cases, antenatal diagnosis is possible. ${ }^{9}$ Asymptomatic EL sequestration may not need any treatment. However, resection is required for IL sequestration. ${ }^{10}$ Ligation/embolization of the systemic arterial supply in asymptomatic patients or in presence of cardiac failure may be advisable for IL sequestration. ${ }^{11}$ In our series, of the three patients, two had EL and one had IL sequestration. Left lower lobectomy was performed for the IL sequestration. The EL sequestration in both the patients could be excised without injury to the adjacent lungs ( $\mathbf{- F i g . ~ 4 A , ~ B ) . ~ T h e ~ c h i l d ~ w i t h ~}$ IL sequestration needed ventilator support for 8 postoperative days. All the three children had recovered well and have been in good health at follow-up.

Mullassery and Jones reported on 41 children with lung malformations treated with open lung resection with excellent clinical outcome. ${ }^{12}$ Recent technologic advances in instrumentation, energy sources, and technique have now 


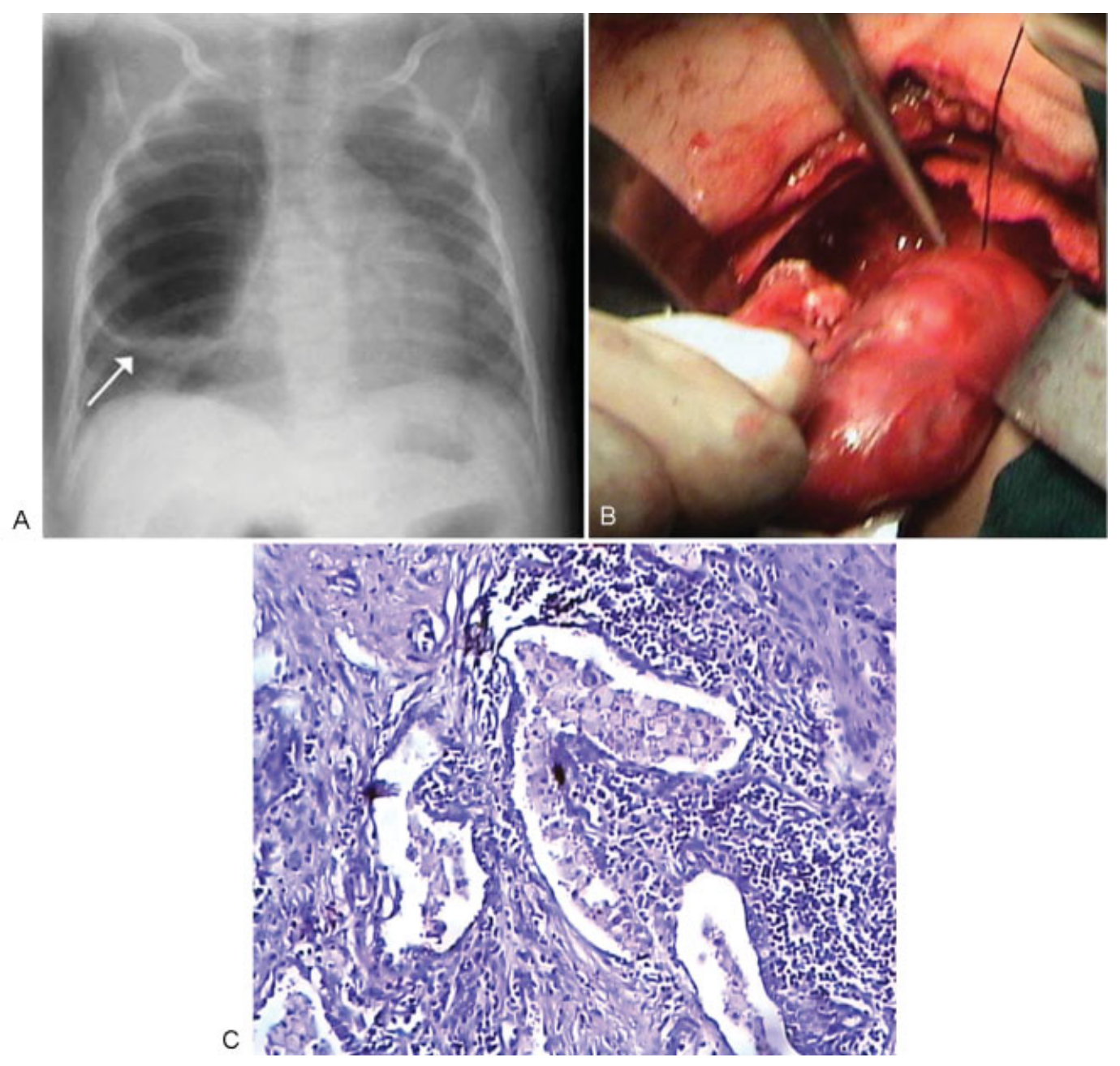

Fig. 3 (A) Chest X-Ray of a child with bronchogenic cyst. (B) Bronchogenic cyst being excised. (C) Microphotograph showing cartilage, muscles, and respiratory epithelium on the wall. Hematoxylin and eosin stain, $10 \times 100$.

made formal anatomic lobectomy using thoracoscopic techniques a much more feasible and safe procedure. Rothenberg et al reported their experience on thoracoscopic lobectomy in 65 children with CCAM and 9 with CLE with a satisfactory outcome. ${ }^{13}$ Around $3 \%$ of their children needed conversion to open thoracotomy. Adzick et al reported 134 cases of antenatally detected CCAM; 14 had an elective abortion, 101 patients were managed expectantly, of which 38 later

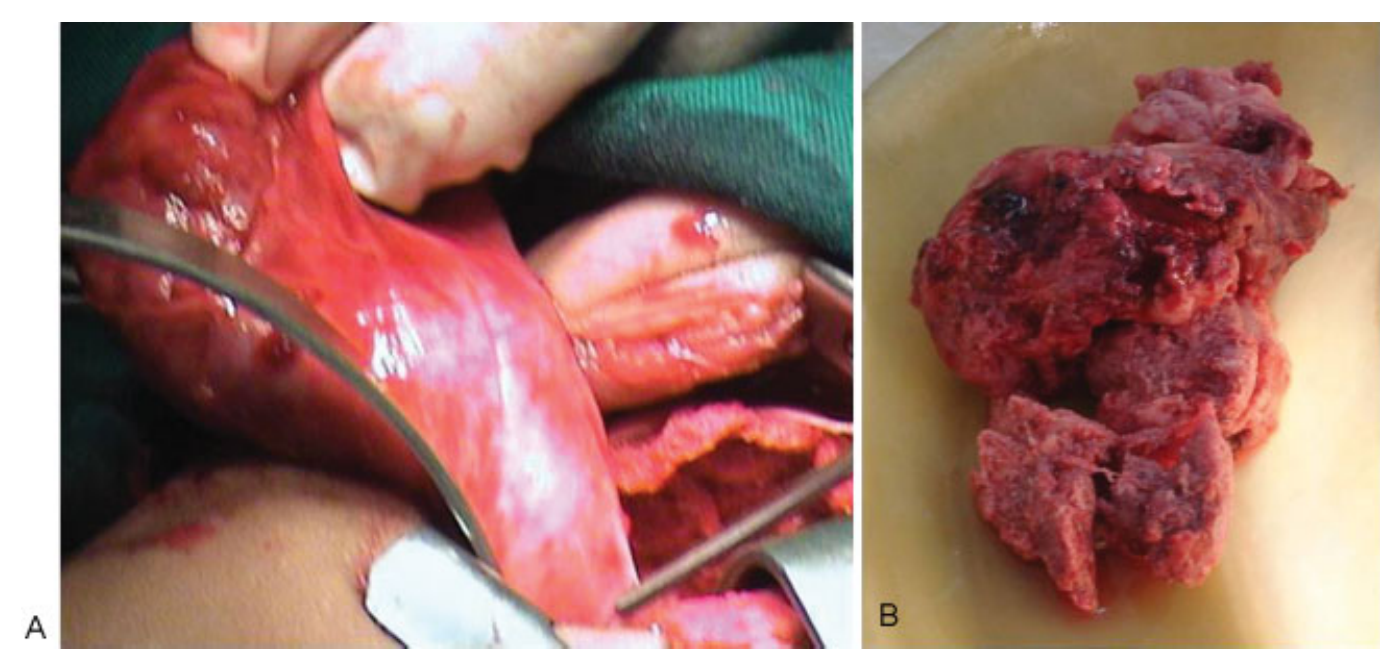

Fig. 4 (A) Extrapulmonary sequestration being excised. (B) The excised specimen of sequestration. 
developed nonimmune hydrops. ${ }^{14}$ A total of 25 fetuses in the latter group were managed expectantly, and all of them died. Antenatal intervention between weeks 21 and 29 was done in 13 fetuses, of which 8 survived. The thoracoamniotic shunt was done in another six fetuses of the expectant therapy group of which five survived.

Outcome following lung resection depends on the age of the child, nature of the original condition, residual disease, and on the amount of the lung resected. Lung resection is considered to be safe and well tolerated during infancy. ${ }^{15}$ One study observed that most children undergoing lobectomy had a normal long-term pulmonary function, and there was no correlation between age at lobectomy and future pulmonary function. ${ }^{16}$ Werner et al reported that lung resection in early childhood leads to good functional recovery. ${ }^{17}$ However, decreased expiratory flows, regional ventilation abnormalities, and decreased perfusion suggested dysplastic parenchyma and vascular bed in the area of resection. Cook and Bucci reported reduced lung volume and diffusing capacity, approximately by the amount predictable for the size of the lung resected. ${ }^{18}$ Frenckner and Freyschuss found that there was complete volume compensation following upper lobectomy and none after middle lobectomy. ${ }^{19}$ The authors also found compensatory growth, but no normalization of physiological measurements. Another study reported complete normalization of lung volumes after lobectomy for CLE. ${ }^{20}$

Nakajima et al showed more compensatory lung growth in children aged $<4$ years at surgery. ${ }^{21}$ However, Keijzer et al reported that early lobectomy does not confer an advantage to the child with respect to long-term pulmonary function. ${ }^{22}$ The authors showed that age at lobectomy ( $>$ 2 years vs. $<2$ years) did not influence FVC and $\mathrm{FEV}_{1}$, assessed at a mean age of 10 years.

Although surgery has been recommended for symptomatic lung lesions, there has been some controversy regarding management of asymptomatic lesions. There were instances when congenital lung lesions undergo spontaneous regression. Hence, surgery for asymptomatic lesions would invite unnecessary iatrogenic complications. ${ }^{23}$ Butterworth and Blair suggested a period of observation for antenatally detected CCAM, as approximately $4 \%$ of these lesions regress spontaneously and may not need surgery at all. ${ }^{24}$ Tsai et al advocated early surgery to avoid complications such as pneumonia, pneumothorax, and malignancy. ${ }^{25}$ Delayed surgery also involves periodic evaluation of the child with X-rays and computed tomography scan, exposing the child to unreasonable radiation exposure, and risk of later development of cancer. ${ }^{26}$ Studies with longer follow-up have shown high complication rate of initially asymptomatic patients. One study reported 18 out of 21 developing symptoms at a median age of 2 years. ${ }^{27}$ Moreover, Stanton et al reviewed the literature on long-term follow-up of congenital lung lesions and found that $3 \%$ of the initially asymptomatic patients developed symptoms during neonatal life. ${ }^{28}$ Complications after emergency surgery were also stated to be high. The authors advocated early surgery, preferably before 10 months of age; and lobectomy was preferable to segmentectomy to avoid leaving residual disease.

Stacher et al studied the development of neoplasia in congenital lung lesions and opined that CCAM and atypical goblet cell hyperplasia predispose to bronchoalveolar carcinoma. ${ }^{29}$ Nasr et al found incidence of pleuropulmonary blastoma among apparently benign congenital lung lesions as $4 \%{ }^{30}$

\section{Conclusion}

Congenital lung malformations are uncommon lesions but may cause significant morbidity and mortality. Proper antenatal and neonatal identification of such lesions are important to provide optimal care. Surgical removal of such lesions is a reasonable option to avoid serious complications.

\section{References}

1 Gross RE, Lewis JE, Jr. Defects of the anterior mediastinum. Successful surgical repair. Surg Gynecol Obstet 1945;80:549-554

2 Rodgers BM. The role of thoracoscopy in pediatric surgical practice. Semin Pediatr Surg 2003;12(01):62-70

3 Kravitz RM. Congenital malformations of the lung. Pediatr Clin North Am 1994;41(03):453-472

4 Stanton M, Davenport M. Management of congenital lung lesions. Early Hum Dev 2006;82(05):289-295

5 Thakral CL, Maji DC, Sajwani MJ. Congenital lobar emphysema: experience with 21 cases. Pediatr Surg Int 2001;17(2-3):88-91

6 Tapper D, Schuster S, McBride J, et al. Polyalveolar lobe: anatomic and physiologic parameters and their relationship to congenital lobar emphysema. J Pediatr Surg 1980;15(06):931-937

7 Moerman P, Fryns JP, Vandenberghe K, Devlieger H, Lauweryns JM. Pathogenesis of congenital cystic adenomatoid malformation of the lung. Histopathology 1992;21(04):315-321

8 Stocker JT, Madewell JE, Drake RM. Congenital cystic adenomatoid malformation of the lung. Classification and morphologic spectrum. Hum Pathol 1977;8(02):155-171

9 Dolkart LA, Reimers FT, Helmuth WV, Porte MA, Eisinger G. Antenatal diagnosis of pulmonary sequestration: a review. Obstet Gynecol Surv 1992;47(08):515-520

10 Louie HW, Martin SM, Mulder DG. Pulmonary sequestration: 17-year experience at UCLA. Am Surg 1993;59(12):801-805

11 Wensley DF, Goh TH, Menahem H, Edis B, Venables AW. Management of pulmonary sequestration and Scimitar syndrome presenting in infancy. Pediatr Surg Int 1989;4:381-385

12 Mullassery D, Jones MO. Open resections for congenital lung malformations. J Indian Assoc Pediatr Surg 2008;13(03):111-114

13 Rothenberg SS. Thoracoscopic pulmonary surgery. Semin Pediatr Surg 2007;16(04):231-237

14 Adzick NS, Harrison MR, Flake AW, Howell LJ, Golbus MS, Filly RA. Fetal surgery for cystic adenomatoid malformation of the lung. J Pediatr Surg 1993;28(06):806-812

15 Aspirot A, Puligandla PS, Bouchard S, Su W, Flageole H, Laberge JM. A contemporary evaluation of surgical outcome in neonates and infants undergoing lung resection. J Pediatr Surg 2008; 43(03):508-512

16 Naito Y, Beres A, Lapidus-Krol E, Ratjen F, Langer JC. Does earlier lobectomy result in better long-term pulmonary function in children with congenital lung anomalies? A prospective study. J Pediatr Surg 2012;47(05):852-856

17 Werner HA, Pirie GE, Nadel HR, Fleisher AG, LeBlanc JG. Lung volumes, mechanics, and perfusion after pulmonary resection in infancy. J Thorac Cardiovasc Surg 1993;105(04):737-742 
18 Cook CD, Bucci G. Studies of respiratory physiology in children. IV. The late effects of lobectomy on pulmonary function. Pediatrics 1961;28:234-242

19 Frenckner B, Freyschuss U. Pulmonary function after lobectomy for congenital lobar emphysema and congenital cystic adenomatoid malformation. A follow-up study. Scand J Thorac Cardiovasc Surg 1982;16(03):293-298

20 McBride JT, Wohl MEB, Strieder DJ, et al. Lung growth and airway function after lobectomy in infancy for congenital lobar emphysema. J Clin Invest 1980;66(05):962-970

21 Nakajima C, Kijimoto C, Yokoyama Y, et al. Longitudinal follow-up of pulmonary function after lobectomy in childhood - factors affecting lung growth. Pediatr Surg Int 1998;13(5-6):341-345

22 Keijzer R, Chiu PP, Ratjen F, Langer JC. Pulmonary function after early vs late lobectomy during childhood: a preliminary study. J Pediatr Surg 2009;44(05):893-895

23 Nagata K, Masumoto K, Tesiba R, et al. Outcome and treatment in an antenatally diagnosed congenital cystic adenomatoid malformation of the lung. Pediatr Surg Int 2009;25(09):753-757

24 Butterworth SA, Blair GK. Postnatal spontaneous resolution of congenital cystic adenomatoid malformations. J Pediatr Surg 2005;40(05):832-834
25 Tsai AY, Liechty KW, Hedrick HL, et al. Outcomes after postnatal resection of prenatally diagnosed asymptomatic cystic lung lesions. J Pediatr Surg 2008;43(03):513-517

26 Brenner D, Elliston C, Hall E, Berdon W. Estimated risks of radiation-induced fatal cancer from pediatric CT. Am J Roentgenol 2001;176(02):289-296

27 Wong A, Vieten D, Singh S, Harvey JG, Holland AJ. Long-term outcome of asymptomatic patients with congenital cystic adenomatoid malformation. Pediatr Surg Int 2009;25(06): 479-485

28 Stanton M, Njere I, Ade-Ajayi N, Patel S, Davenport M. Systematic review and meta-analysis of the postnatal management of congenital cystic lung lesions. J Pediatr Surg 2009;44(05): 1027-1033

29 Stacher E, Ullmann R, Halbwedl I, et al. Atypical goblet cell hyperplasia in congenital cystic adenomatoid malformation as a possible preneoplasia for pulmonary adenocarcinoma in childhood: A genetic analysis. Hum Pathol 2004;35(05): 565-570

30 Nasr A, Himidan S, Pastor AC, Taylor G, Kim PC. Is congenital cystic adenomatoid malformation a premalignant lesion for pleuropulmonary blastoma? J Pediatr Surg 2010;45(06):1086-1089 